\section{Leadshot: An Unusual Cause of Stent Occlusion}

A 76-year-old man had inoperable carcinoma of the head of the pancreas that had been diagnosed three months previously, and had a $10-\mathrm{Fr}, 7-\mathrm{cm}$ Cotton-Leung biliary stent placed for palliation. He was well until two days prior to this admission, when he developed cholangitis. Endoscopic retrograde cholangiopancreatography (ERCP) was performed for presumed stent occlusion. At ERCP, the control radiograph showed a radiopaque foreign body, leadshot, projected over the plastic stent (Figure 1). On direct inspection of the duodenum, the stent was in a satisfactory position, but no bile was draining. The stent was successfully exchanged. The removed stent was radiographed after the procedure, and this showed that the leadshot was impacted in the lumen of the upper portion of the stent below the proximal side hole (Figure 2), causing complete stent occlusion.

Foreign bodies in the biliary tree are an uncommon cause of obstructive jaundice. In Asia, parasites (1) are frequent, presumably migrating via the papilla. In Western societies, forcign bodies are usually surgical materials (2), which migrate into the biliary tract and act as nidi for stones. There are a few reported cases of shrapnel from previous penetrating trauma to the liver migrating through soft tissues to lodge in the biliary tree (3). Ingested forcign bodies migrating into the bile ducts usually occur in patients with previous surgery to the papilla of Vater, or where a bilioenteric anastomosis has been created. Accidental ingestion of sharp objects has resulted in penetration of the duodenal wall and passage into the biliary tree (4). Rarely, ingested foreign bodies have migrated through the intact papilla (5).

The case presented here is, to our knowledge, the first report of stent occlusion by a biliary foreign body. The leadshot must have been ingested, and on questioning, the patient did admit to having eaten rabbit meat in the days prior to his presentation. More interesting is the mechanism of passage of the leadshot into the stent. It is known that placement of transpapillary stents results in enterobiliary reflux, but considerable duodenal pressure must have been achieved for the leadshot to lodge in the stent, resulting in occlusion.

\section{R. England. D. Martin}

Dept. of Radiology, South Manchester University Hospitals, Manchester, United Kingdom

\section{References}

1. Schulman A. Non-Western patterns of biliary stones and the role of ascariasis. Radiology $1987 ; 162 ; 425-30$.

2. Garcia JC, Lemarchand F, Samama G. Foreign bodies in the biliary tract, 1: postoperative foreign bodies in the biliary tract. A review of seventy-one cases reported in the literature and four cases treated personally. Ann Chir 1982; 36: 437-41.

3. Mitchell, R, Kerr R, Barton J, Schmidt A. Biliary obstruction secondary to shrapnel. Am J Gastroenterol 1991; 86: 1531 -4.

4. Ban JL, Hirose FM, Benfield JR. Foreign bodies of the biliary tract: report of two patients and a review of the literature. Ann Surg 1972: 176: 102-7,

5. Kelly MD. Hugh TB. Cherry stalk in the common bile duct. Aust NZ J Surg 1993; 63: 571 -4.

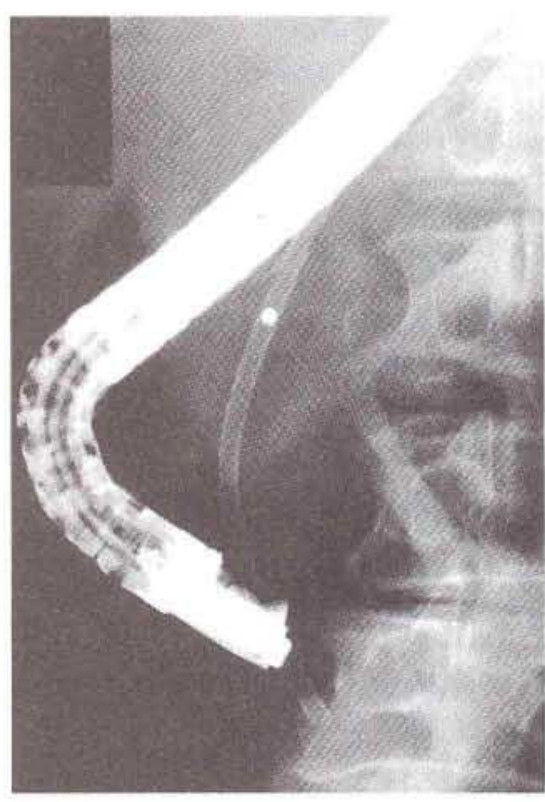

Figure 1: The control radiograph prior to stent exchange shows a metallic foreign body projected over the proximal portion of the stent. Note the absence of biliary air, suggesting stent occlusion.

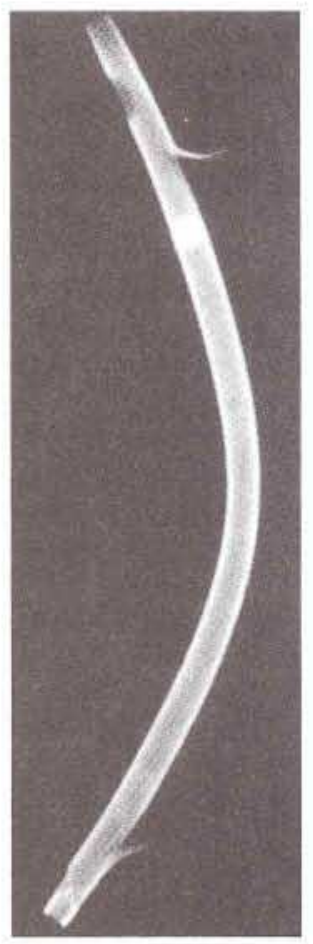

Figure 2: The stent was radiographed after removal from the patient, confirming the presence of an impacted piece of leadshot.

Corresponding Author

R. E. England, M. D.

Dept. of Radiology

South Manchester University Hospitals

N.H.S. Trust

Withington. Nell Lane

Manchester M20 2LR

United Kingdom

Fax: $+44-161-448-1688$ 